\title{
Electrographic Seizures in Preterm Infants During the First Week of Life Are Associated With Cerebral Injury
}

\author{
DIVYEN K. SHAH, JOHN ZEMPEL, TONY BARTON, KAREN LUKAS, AND TERRIE E. INDER
}

Departments of Pediatrics [D.K.S., T.B., K.L., T.E.I.] and Neurology [J.Z.], Washington University, St Louis, Missouri 63110

\begin{abstract}
The aim of the study was to determine the incidence of electrographic seizure activity in a prospective cohort of preterm infants and relate it to the presence of cerebral injury. Infants born $<30$-wk gestation received a median $74 \mathrm{~h}$ of continuous 2-channel EEG with amplitude-integrated EEG monitoring in the first week of life. Infants were classified in the abnormal outcome group if they died in the neonatal period and/or had grades 3-4 intraventricular hemorrhage and/or moderate or severe abnormalities on cerebral MRI. Seizures were defined as rhythmic spike and/or wave activity lasting at least $10 \mathrm{~s}$ on the raw EEG trace. Eleven of 51 infants monitored had electrographic seizures. These infants were more premature had lower birth weights and a greater proportion had abnormal outcomes. In four infants, seizures preceded ultrasound findings of grades 3-4 intraventricular hemorrhage. Three of the four infants with seizures and concurrent physiologic recordings displayed concurrent rises in heart rate and one showed a fall in respiratory rate. In conclusion, electrographic seizures were more likely to occur in the sicker and more premature infants with abnormal outcomes. Seizures detected on continuous amplitude-integrated EEG monitoring with the raw EEG were associated with poor outcome. (Pediatr Res 67: 102-106, 2010)
\end{abstract}

$\mathrm{E}^{\mathrm{lec}}$ lectrographic seizures are an important manifestation of neurologic disease in the newborn period (1) and are associated with adverse neurodevelopmental outcomes (2). Population-based studies suggest that clinical seizures occur more frequently in low birth weight infants $(1,3)$. Seizures in preterm infants have been noted to be associated with cerebral pathology, such as intraventricular hemorrhage (IVH), and commonly occur in the first $48 \mathrm{~h}$ of life (4). However, information regarding the frequency, clinical, and neuropathological correlates of electrographic seizure activity in preterm infants is limited.

Amplitude-integrated EEG (aEEG) has been used to monitor electrographic seizures in the at-risk newborn in the neonatal intensive care unit (NICU) (5). The aEEG trace is produced after a raw EEG signal is amplified, rectified, smoothed, semi-log transformed, and compressed so that typically a 6-cm trace represents 1 hour of recording (6). Our data suggest that three quarters of electrographic seizures in termborn infants may be detected off-line using the aEEG with the raw EEG trace, when limited channel digital aEEG monitors are used by experienced raters (7). Although not all electrical

Received April 16, 2009; accepted August 29, 2009.

Correspondence: Divyen K. Shah, M.B., Ch.B., Department of Neonatology, The Royal London Hospital, Whitechapel, London EC1, United Kingdom; e-mail: divyenshah@doctors.org.uk

Equipment support for the study was provided by BrainZ Instruments, NZ. seizures will be detected with the limited number of channels (8), the longer period of monitoring facilitated by these systems may allow detection of electrographic seizure activity that may otherwise not be captured during a routine shorter conventional EEG (7). In preterm infants, aEEG monitoring remains a research tool.

The aim of this study was to determine the prevalence of electrographic seizure activity in a prospective cohort of preterm infants $(<30$-wk gestation) using 2-channel digital EEG with aEEG monitoring during the first week of life. For preterm infants with electrographic seizures, the aims were to further characterize the timing, morphology, and presence of associated autonomic changes of these seizures and to understand their relationship to cerebral injury.

\section{METHODS}

Population. Between April 2007 and June 2008, infants under 30-wk gestation referred to St. Louis Children's Hospital neonatal intensive care unit were prospectively recruited to an aEEG monitoring cohort study, with informed consent from the family. The study had received previous approval from the local Institutional Research Board.

$\boldsymbol{E E G}$ with aEEG monitoring. Infants were monitored with 2-channel (C3-P3, C4-P4) EEG with aEEG using the digital BRM2 (BrainZ Instruments, New Zealand) and hydrogel electrodes. Video monitoring was not performed as part of this study, however, if seizures were suspected by the attending physician, video monitoring was performed independently as part of the local management protocol.

Physiologic parameters. When technically feasible, the bedside physiologic parameters [blood pressure, heart rate (HR) and respiratory rate (RR), and oxygen saturations] were downloaded continuously from the bedside "vital signs" monitor directly to the aEEG monitor while the infant underwent aEEG monitoring. The recording of physiologic parameters was limited due to the lack of an RS232 connection port, necessary for communication with the aEEG monitor, on vital signs monitors at the bedsides of many of the enrolled infants.

Visual analysis of aEEG for electrographic seizure activity. The recordings were visually inspected for seizures using the digital aEEG with confirmation by the two channels of raw EEG by a neonatologist (D.K.S.) and confirmed by a neurologist with expertise in neurophysiology (J.Z.). Seizures were defined as a minimum 10 -s period of rhythmic, repetitive activity seen on the 2-channel EEG, as previously described (7). Seizure morphology as seen on these two channels was described in terms of the frequency of the rhythmic activity, as well as nature of the waveforms based on commonly used clinical descriptions (spikes, sharp waves, spike and wave, polyspike and wave, sharp and wave) (9).

Correlation of aEEG with physiologic parameters in infants with seizures. For each infant with electrographic seizures for whom physiologic data were downloaded, an attempt was made to identify the relationship between the change in EEG activity with HR and RR. The aEEG segments for the first

Abbreviations: aEEG, amplitude-integrated EEG; CPAP, continuous positive airway pressure; CUS, cranial ultrasound; HR, heart rate; IVH, intraventricular hemorrhage; IPPV, intermittent positive pressure ventilation; PCA, post-conceptional age 
five seizures from each infant were digitally filtered (Chebyshev) and down sampled (from 8 to $0.4 \mathrm{~Hz}$ ) using Matlab 7 (Natick, MA) to the base frequency of the RR and HR data. Onset of change (if any) in the RR and HR, time and magnitude of peak change, and return to baseline of the physiologic data were determined.

Neuroimaging. As per local clinical practice, infants had their first cranial ultrasound (CUS) in the first 3 days of life, then on $\mathrm{d} 7-10,14$, and 28 routinely unless otherwise indicated. MRI was carried out at term corrected age.

Cerebral injury. Infants were categorized into the adverse outcome group if they developed grade 3 or $4 \mathrm{IVH}$ and/or had moderate or severe white matter abnormality on MRI at term and/or died for any reason. The remaining infants were categorized into the normal/mildly abnormal outcome group. The system used to classify the MR white matter abnormalities has been described previously (10).

Statistical analysis. Data analysis was carried out using SPSS version 15.0 (Chicago, IL). Proportions were compared using Fisher's Exact test and Pearson's $\chi^{2}$ statistic. Means were compared using the Student $t$ test for independent samples. If Levene's test yielded a $p<0.05$ then unequal variance in the samples was assumed. Nonparametric data were compared using the Mann Whitney $U$ test. A logistic regression model was used to calculate odds ratios with a covariate.

\section{RESULTS}

Study population. Fifty-seven of 121 (47\%) eligible infants who came through the NICU during this time period were recruited. Infant recruitment was limited by parental refusal $(n=25)$ and availability of monitoring equipment $(n=39)$. The characteristics of the infants recruited were similar to those of the 64 not recruited. The infants not recruited were 26.9- (SD 1.4) wk mean gestation; 7 of 64 (11\%) having had grade $3 / 4 \mathrm{IVH}$ and 9 of 64 (14\%) dying.

Of the 57 infants recruited, two families including four infants withdrew consent Of these two families, there was disagreement between the parents as to whether consent should be provided for this study in one family, and the other family viewed the monitoring as an "unnecessary addition" to all the monitoring their infants were already undergoing. Of the remainder, one infant died before the recording was commenced and the recording for one infant was not available for analysis. Thus, 51 recordings in the first week of life for infants $<30$-wk gestation at birth were analyzed. The mean gestation of the infants studied was 26.6 (SD 1.6) weeks.

Electrographic seizure activity. The commencement of the recording was determined by the availability of parental consent obtained after birth of the infant and the EEG recording equipment. We aimed for an optimum period of recording of $72 \mathrm{~h}$. The aEEG recording was commenced at a median age of 24 (range, 3-117) h for a median period of 74 (range, 12-140) h. Eleven of the $51(22 \%)$ preterm infants displayed seizures during monitoring. Table 1 compares the characteristics of infants who had seizures with the remaining cohort. Seizures were first noted at a median age of 26 (range 6-72) h of life (Table 2). All infants displayed onset of seizures at or before $72 \mathrm{~h}$ of age. The period of seizure activity ranged from $<15$ min to $4 \mathrm{~h}$ and status. In all infants except patient $\mathrm{E}$ (who went into status) the seizure activity was seen to disappear before the end of the recording.

Only two of the 11 infants with seizures (Table 2, infants E and G) displayed clinical seizure activity. These infants had an EEG-video study, as per local clinical protocol, which confirmed seizure activity, and the infants were treated with anticonvulsant medications. Treatment for seizures was car-
Table 1. Characteristics of infants with seizures compared with those without

\begin{tabular}{lcccc}
\hline & Seizures & No seizures & Statistic & $p$ \\
\hline Male & $7 / 11(64 \%)$ & $15 / 40(38 \%)$ & $\chi^{2}=2.4$ & 0.11 \\
$\begin{array}{l}\text { Gestation (wk); } \\
\quad \text { mean (SD) }\end{array}$ & $25.5(1.5)$ & $26.9(1.4)$ & $1.4(0.4,2.4)^{*}$ & 0.006 \\
$\begin{array}{l}\text { Birthweight (g); } \\
\quad 755(130)\end{array}$ & $925(220)$ & $170(62,277)^{*}$ & 0.003 \\
$\quad$ mean (SD) & & & & \\
Apgar 5 min; & $7(0.9)$ & $6(1,9)$ & $Z=-1.32$ & 0.20 \\
$\quad$ median (range) & & & & \\
No IVH & $3 / 11(27 \%)$ & $31 / 40(77 \%)$ & $\chi^{2}=9.8$ & 0.002 \\
IVH grade 3/4 & $5 / 11(45 \%)$ & $3 / 40(7 \%)$ & $\chi^{2}=9.4$ & 0.008 \\
Abnormal outcome & $9 / 11(82 \%)$ & $8 / 40(20 \%)$ & $\chi^{2}=14.8$ & $<0.001$ \\
Died & $5 / 11(45 \%)$ & $2 / 40(5 \%)$ & $\chi^{2}=11.9$ & 0.003 \\
\hline
\end{tabular}

* Mean difference $(95 \% \mathrm{CI})$.

ried out at the discretion of the attending clinician and not on the basis of findings from the study. Ten of the 11 infants had seizures of low frequency ( $\leq 1 \mathrm{~Hz}$ ) (Fig. 1) and one infant (infant J) displayed a rapid spiking rhythm of $\sim 5 \mathrm{~Hz}$.

Seizures, aEEG, and autonomic changes. Physiologic parameters were downloaded for 18 of $51(35 \%)$ infants. Four of these infants had seizure activity on the 2-channel EEG with aEEG recordings.

Of the four infants with seizures and physiologic recordings, three displayed alterations in HR and RR. Infant $\mathrm{E}$ had suffered perinatal hypoxia-ischemia. His aEEG background showed depressed lower and upper margins with burst suppression and a lack of variability. Multiple seizures were clearly seen with distinct rises in the lower and upper aEEG margins and low-frequency sharp wave activity on the raw EEG traces. This subsequently evolved into status epilepticus ( $>50 \%$ seizure activity/h). This infant had clinical seizures and a simultaneous conventional EEG-video study, ordered on a clinical basis, revealed frequent seizure activity. He displayed multiple rises in HR $(15 \pm 4 \%)$ and drops in RR $(69 \pm 4 \%)$ coinciding with the onset of seizure activity as was clearly demonstrated off-line (Fig. 2).

Infant I, born at 24-wk gestation, had multiple lowfrequency seizures, which preceded the CUS finding of grade 3/4 IVH. This infant did not demonstrate clinical seizures but did have rises in HR concurrent with the seizures (Fig. 2). Infant $\mathrm{J}$ had multiple seizures, but on only one occasion was there a coincidental rise in the lower aEEG margin and HR that rose from 127 to $220 \mathrm{bpm}$.

Seizures and adverse outcomes. The clinical characteristics of the infants who had seizures are described in Table 3. Infants with seizures had an odds ratio of 18 (95\% CI, 3-100) for an adverse outcome. On controlling for gestational age, the odds ratio was 14 (95\% CI, 2-86) per week of gestational age. Of 17 infants in the adverse outcome group, nine infants $(53 \%)$ had seizures (Fisher's Exact Test, $\chi^{2}=14.8, p<$ $0.001)$.

Seizures and grade 3/4 IVH. In the complete cohort, eight infants had IVH grade 3 or 4 . Five of these eight infants had seizures. Infant $\mathrm{E}$ had suffered perinatal hypoxia-ischemia, and the IVH was noted on the first CUS within $24 \mathrm{~h}$ of birth (Table 2). In the remaining four infants, seizures were noted before high-grade IVH was detected on CUS, with the infants 
Table 2. Characteristics of seizures

\begin{tabular}{|c|c|c|c|c|c|c|c|c|c|c|c|}
\hline Patient & $\begin{array}{l}\text { Gestation } \\
\text { (wk) }\end{array}$ & $\begin{array}{l}\text { Age }(\mathrm{h}) \text { of } \\
\text { commencing } \\
\text { monitoring }\end{array}$ & $\begin{array}{l}\text { Age }(\mathrm{h}) \\
\text { at first } \\
\text { seizure }\end{array}$ & $\begin{array}{c}\text { Seizures } \\
\mathrm{h} / \mathrm{d}\end{array}$ & $\begin{array}{c}\text { Seizure } \\
\text { frequency } \\
(\mathrm{Hz})\end{array}$ & Seizure morphology & $\begin{array}{l}\text { Clinical } \\
\text { correlate }\end{array}$ & $\begin{array}{c}\text { aEEG } \\
\text { background } \\
\text { variability }\end{array}$ & $\begin{array}{l}\text { Grade } \\
\text { IVH } \\
(\mathrm{L}, \mathrm{R})\end{array}$ & $\begin{array}{c}\text { Age }(\mathrm{h}) \text { of } \\
\text { previous } \\
\text { normal CUS }\end{array}$ & $\begin{array}{c}\text { Age }(h) \text { at } \\
\text { abnormal } \\
\text { CUS }\end{array}$ \\
\hline A & 27 & 7 & 12 & 0.5 & 0.5 & Slow waves & No & Present & Nil & & \\
\hline $\mathrm{B}$ & 26 & 12 & 24 & 1 & 0.5 & Spike & No & Present & Nil & & \\
\hline $\mathrm{C}$ & 28 & 22 & 36 & 0.5 & $0.5-1$ & Spike and wave & No & Absent no & Nil & & \\
\hline $\mathrm{D}$ & 23 & 7 & 10 & 1 & $0.5-1$ & Polyspike and wave & No & Absent & 2,2 & 28 & 98 \\
\hline $\mathrm{E}$ & 28 & 11 & 12 & 4 then status & 0.5 & Sharp & Yes & Absent & 1,4 & 12 & 84 \\
\hline $\mathrm{F}$ & 25 & 28 & 36 & $<0.25$ & $<0.5$ & Polyspike and wave & No & Absent no & 3,3 & 25 & 72 \\
\hline G & 25 & 27 & 30 & 1 & $0.5-1$ & Sharp & Yes & Present & 3,3 & 20 & 45 \\
\hline $\mathrm{H}$ & 24 & 6 & 6 & 2 & $0.5-1$ & Sharp & No & Absent no & 1,1 & 26 & 73 \\
\hline I & 24 & 30 & 30 & 3 & $0.5-1$ & Polyspike and wave & No & Absent yes & 4,3 & 7 & $5 \mathrm{~d}$ \\
\hline $\mathrm{J}$ & 25 & 29 & 30 & 0.5 & 5 & Spike & No & Absent & 3,4 & 19 & 42 \\
\hline $\mathrm{K}$ & 26 & 71 & 72 & $<0.25$ & 1 & Spike & No & Present & 1,1 & 94 & $1 \mathrm{wk}$ \\
\hline
\end{tabular}

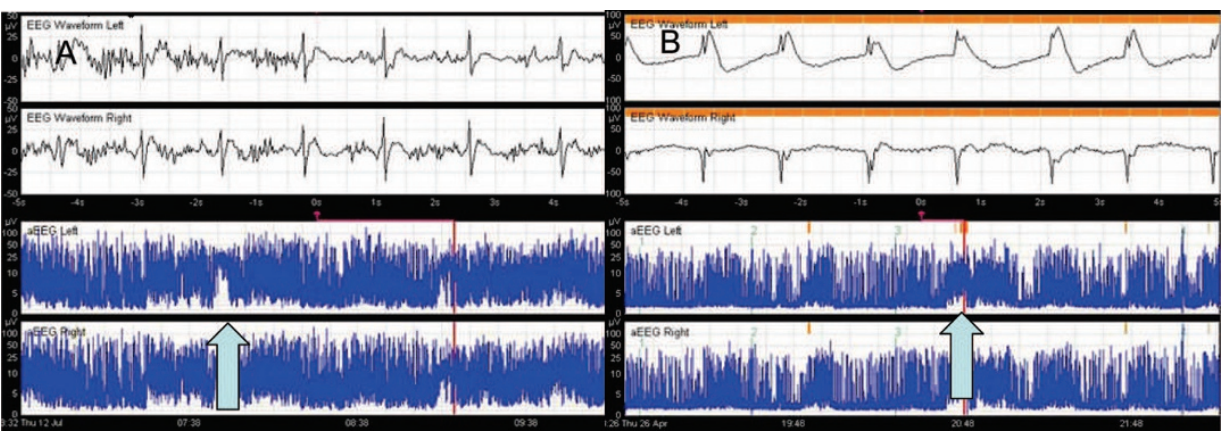

Figure 1. Electrographic seizures as seen in patients B (panel A) and D (panel B). In both patients, at the rise in the lower margin of the aEEG (arrows) there is polyspike activity between 0.5 and $1 \mathrm{~Hz}$ on the raw EEG traces.

having had a previous unremarkable CUS. A larger proportion of infants in the no seizures detected group were free of IVH (Table 2).

Seizures and death. Five of the 11 infants (45\%) with seizures died compared with 2 of $40(5 \%)$ without seizures (Fisher's Exact Test, $\chi^{2}=11.9, p=0.003$ ) (Table 2). Of the five infants with seizures who died, one had catastrophic IVH (infant $\mathrm{J}$ ), one had suffered severe hypoxia-ischemia (infant $\mathrm{E}$ ), and two died of fulminant NEC in the ensuing weeks (infants D and F). One infant (infant K) had suffered NEC in the first week of life requiring insertion of an abdominal drain but died of end-stage respiratory failure and sepsis.

\section{DISCUSSION}

Twenty-two percent of infants under 30-wk gestation in this cohort displayed seizures on digital 2-channel aEEG with raw EEG monitoring in the first week of life. Infants who had seizures were more likely to be immature and were at greater risk for poor outcomes than those who did not, even after controlling for gestational age. Hence, seizures were more commonly seen in the small very sick preterm infants in the first $48 \mathrm{~h}$ of life who had cerebral injury including high-grade IVH.

Electrographic seizure activity on conventional EEG has been recognized in the preterm infant in association with IVH (11) and adverse neurologic sequela (12). Epidemiologic data suggest that it is more common in infants of low birth weight (1,3). Scher et al. (4) described 92 newborns with electrographic seizures, recorded over a $4-y$ period at a single center. Two-thirds were preterm and almost one half of these displayed electrographic seizures in the first $48 \mathrm{~h}$ of life. Most of the preterm infants had cerebral lesions, with half having IVH with either ventricular dilatation or intraparenchymal extension (grade 3 or 4 ).

Using analog aEEG without the raw EEG trace, HellstromWestas et al. (13) described activity thought to represent electrographic seizure activity in three quarters of a group of preterm infants under $1 \mathrm{~kg}$ at birth, who had IVH. A more recent study, also using aEEG alone, described increasing likelihood of suspected seizures on the aEEG with worsening grade of IVH in preterm infants during the first 2 wk of life (14). In our cohort, using digital aEEG with raw EEG, five of the eight infants with grade $3 / 4$ IVH were noted to have seizures. In four of these five, seizures were noted before an abnormal CUS, the infants previously having had a normal CUS. Thus, seizures may represent a marker of an evolving cerebral insult and/or cerebral irritability from the IVH.

The amygdala, insular cortex, and hippocampus are thought to be important structures for the autonomic regulation of $\mathrm{HR}$ and rhythm (15). Hence, ictal tachycardia commonly accompanies temporal lobe epileptic seizures and in a substantial proportion of epileptic patients precedes the electrographic seizure detected at the scalp (16). Importantly, experimental studies demonstrate that autonomic changes accompanying seizures may be an adaptation response to increased metabolic demands during seizures (17).

However, data on autonomic activity associated with seizures in newborns are more limited. An EEG study of seizures in 14 severely asphyxiated neonates found a change in HR accompanied only $12 \%$ of individual seizures but occurred in 8 of $14(57 \%)$ infants (18). In their NICU-based EEG study Scher et al. (4) reported that a larger proportion of preterm 


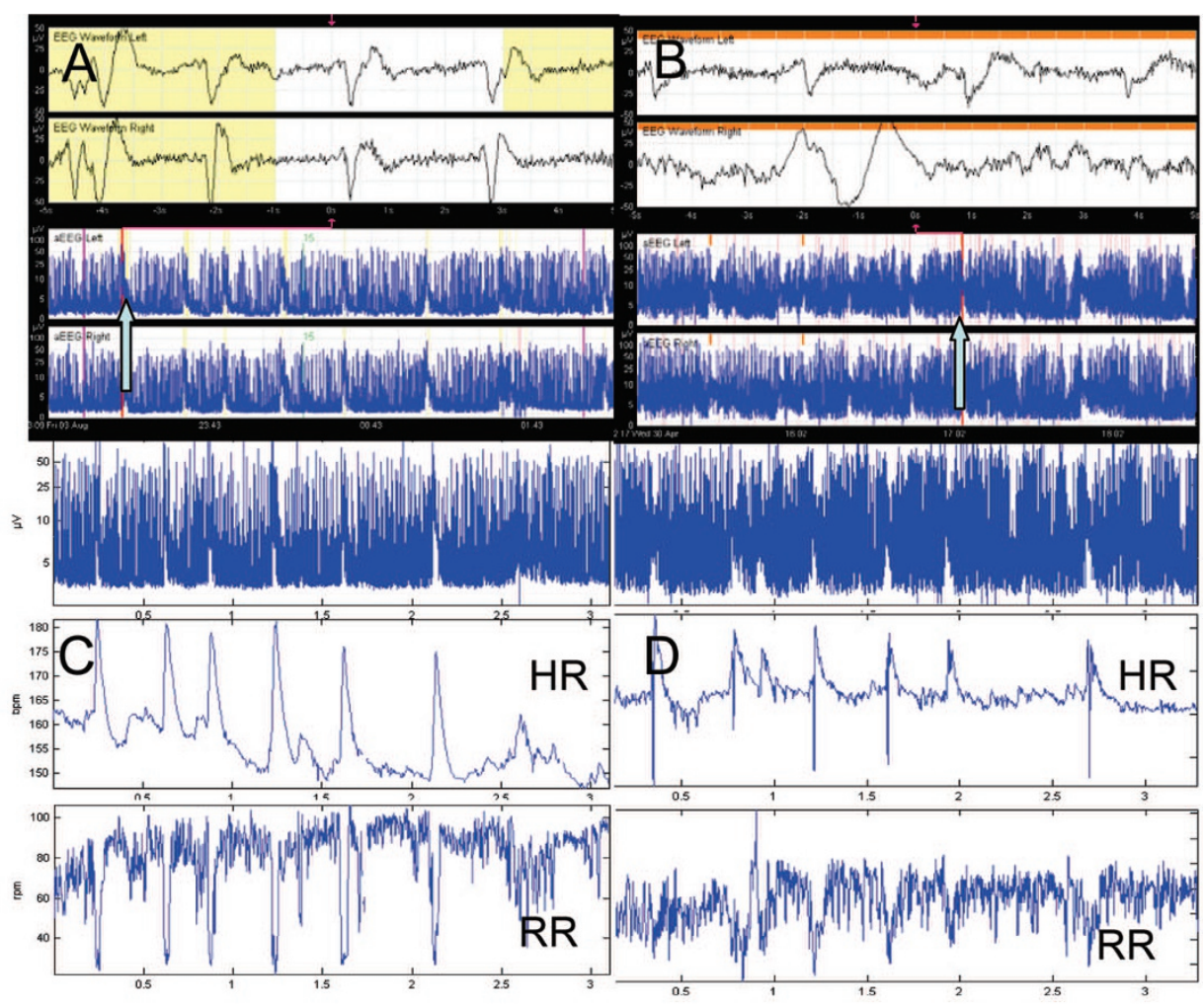

Figure 2. Left panels represent infant $E$ and right panels represent infant I. Lower parts of panels $A$ and $B$ represent the left and right hemisphere aEEG. The arrows on the aEEG correspond to the raw EEG signals above. The raw EEG signal. Panel $A$ shows lowfrequency sharp wave seizure from both hemispheres. Panel B shows low-frequency sharp wave seizure from the left hemisphere (upper trace). Panels $C$ and $D$ show the aEEG trace (upper segment) with corresponding changes in heart (center segment) and respiratory (lower segment) rate. Panel $C$ shows a rise in HR and a decrease in RR corresponding to seizures on the aEEG. Panel $D$ shows changes in HR corresponding to seizures on aEEG. Panels $E$ and $F$ represent the relationship between aEEG (green) with $\mathrm{HR}$ (red) and RR (blue) for the first five consecutive seizures for infants $\mathrm{E}$ (panel $E$ ) and infant I (panel F). Panel $F$ shows that patient I has drops before the rise in HR with no clear relationship between aEEG and RR.
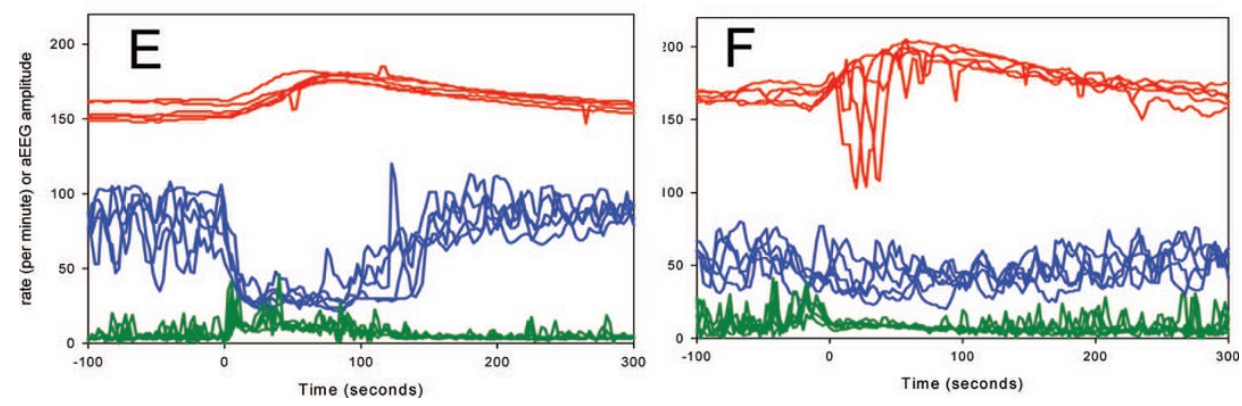

Table 3. Clinical characteristics of infants with seizures

\begin{tabular}{|c|c|c|c|c|c|c|c|c|c|}
\hline Patient & $\begin{array}{l}\text { Gestation } \\
\text { (wk) }\end{array}$ & $\begin{array}{l}\text { Apars } 1,5 \\
\min \end{array}$ & $\begin{array}{c}\text { First } \\
\mathrm{pH}\end{array}$ & $\begin{array}{l}\text { First } \\
\mathrm{pCO}_{2}\end{array}$ & Surfactant & $\begin{array}{l}\text { Respiratory support } \\
\text { during monitoring }\end{array}$ & $\begin{array}{l}\text { Other clinical } \\
\text { details }\end{array}$ & Details & Discharge \\
\hline A & 27 & 8,9 & 7.34 & 48 & No & CPAP & Chorioamnionitis & Normal/mild WMA & Home \\
\hline $\mathrm{B}$ & 26 & 2,7 & 7.54 & 20 & Yes & CPAP & & Normal/mild WMA & Home \\
\hline $\mathrm{C}$ & 28 & 8,9 & 7.38 & 44 & Yes & CPAP & & $\begin{array}{l}\text { Multiple high signal } \mathrm{T} 1 \\
\text { abnormalities throughout } \\
\text { parenchyma }\end{array}$ & Home \\
\hline $\mathrm{D}$ & 23 & 5,7 & 7.41 & 32 & Yes & IPPV & & Overwhelming NEC at $24 \mathrm{~d}$ age & Died \\
\hline $\mathrm{E}$ & 28 & 0,0 & 6.86 & 48 & Yes & IPPV & & $\begin{array}{l}\text { Eclampsia, Apgars 0, 0,2. Multiple } \\
\text { cerebral infarcts }\end{array}$ & Died \\
\hline $\mathrm{F}$ & 25 & 1,1 & 7.36 & 32 & Yes & IPPV & & $\begin{array}{l}\text { Died from overwhelming NEC at } \\
\text { 30-wk PCA }\end{array}$ & Died \\
\hline G & 25 & 3,6 & 7.29 & 45 & Yes & IPPV & & No VP shunt & Home \\
\hline $\mathrm{H}$ & 24 & 3,5 & 7.20 & 55 & Yes & IPPV & $\begin{array}{l}\text { Choriomanionitis, } \\
\text { inotropes }\end{array}$ & $\begin{array}{l}\text { Multiple high signal } \mathrm{T} 1 \\
\text { abnormalities throughout } \\
\text { parenchyma }\end{array}$ & Home \\
\hline I & 24 & 1,4 & 7.19 & 64 & Yes & IPPV & & Porencephalic cyst, VP shunt & Home \\
\hline $\mathrm{J}$ & 25 & 3,6 & 7.29 & 45 & Yes & IPPV & & $\begin{array}{l}\text { Acute compromise from } \\
\text { overwhelming IVH }\end{array}$ & Died \\
\hline $\mathrm{K}$ & 26 & 8,9 & 7.33 & 41 & Yes & CPAP + IPPV & Inotropes & $\begin{array}{l}\text { NEC on day } 5 \text { of life. Severe } \\
\text { BPD and sepsis }\end{array}$ & Died \\
\hline
\end{tabular}

IPPV, intermittent positive pressure ventilation; CPAP, continuous positive airway pressure; WMA, white matter abnormality. 
infants had autonomic changes accompanying seizure activity compared with term infants [7 of 19 (37\%) versus 1 of 16 $(6 \%)]$. Our data in a more limited number of infants $(n=4)$ remain consistent with these observations. The temporal relationship of autonomic changes to the onset of seizures is unclear, other than a delayed and sustained rise in HR, especially given the difficulty of determining seizure onset precisely with the limited number of EEG channels.

Although the waveforms of seizures detected in our cohort span the varieties of waveforms observed in electrographic seizure activity, all but one infant displayed low frequency rhythmicity. A more complete characterization of morphology would require multiple channels of EEG in a larger cohort. A study of characteristics of EEG ictal activity in newborn infants reports that rhythmic delta activity was the most common form of seizure morphology reported in preterm infants (19).

aEEG monitors are commonly used in the NICU as a monitoring tool for electrographic seizures in full-term newborn. Preliminary data suggest that using digital aEEG with the raw EEG, $76 \%$ of electrographic seizures may be detected in term infants, when used off-line by experienced raters (7). One or two channels cannot detect all the electrographic seizure activity detected using multiple channels as short and focal seizures will be missed $(7,20)$ thus, the seizures detected in this study are likely to be an under representation of total seizure activity.

Our study has additional limitations. This is a relatively small cohort study that is not powered to study the impact of seizures on longer term outcomes in survivors. In this study, monitoring was only commenced after informed consent was obtained after the birth of the infant. The median age at commencing aEEG recording was just before median age at first detecting seizure activity; hence, seizure activity before commencing monitoring may have been missed. The attending physicians were not "blinded" to the monitoring and the possibility that management of infants was affected cannot be discounted. It is also possible that clinical seizure activity was not detected, as video monitoring was not used as part of the study. Many infants in the cohort did not have physiologic data available. In addition, the assessment of seizures and its relationship to autonomic changes was carried out off-line.

However, the infants studied were representative of admissions to the NICU and had similar characteristics to infants not recruited. The relatively high incidence $(16 \%)$ of severe IVH in this group of infants may reflect that the recruitment center is a tertiary referral center serving a large geographic catchment and population.

In conclusion, our data show that in a representative group of very preterm infant electrographic seizure activity is not uncommon and is associated with adverse outcomes. The presence of seizures may be a marker for evolution of severe IVH. The association with autonomic changes in three infants in our study and clinical seizure activity in two infants supports that this is true electrographic seizure activity. Further studies with larger cohorts of preterm infants are required to gain a better understanding of the significance of seizures in the preterm infant.

Acknowledgments. We thank the families who participated in this study, the staff of the Neonatal Unit, St. Louis Children's Hospital for their support during this study and also to Jayne Siccard, Jo Ackerman, Jeff Neil, and the Department of Radiology, WA University, and BrainZ Instruments, NZ, for their support of our work throughout the years.

\section{REFERENCES}

1. Volpe JJ 2008 Neurology of the Newborn. W.B. Saunders, Philadelphia, pp 203-245

2. McBride MC, Laroia N, Guillet R 2000 Electrographic seizures in neonates correlate with poor neurodevelopmental outcome. Neurology 55:506-513

3. Lanska MJ, Lanska DJ 1996 Neonatal seizures in the United States: results of the National Hospital Discharge Survey, 1980-1991. Neuroepidemiology 15:117-125

4. Scher MS, Aso K, Beggarly ME, Hamid MY, Steppe DA, Painter MJ 1993 Electrographic seizures in preterm and full-term neonates: clinical correlates, associated brain lesions, and risk for neurologic sequelae. Pediatrics 91:128-134

5. Shah DK, de Vries LS, Hellström-Westas L, Toet MC, Inder TE 2008 Amplitudeintegrated electroencephalography in the newborn: a valuable tool. Pediatrics 122:863-865

6. Hellstrom-Westas L, De Vries LS, Rosen I 2008 Atlas of Amplitude-Integrated EEGs in the Newborn. Informa UK Ltd, London

7. Shah DK, Mackay MT, Lavery S, Watson S, Harvey AS, Zempel J, Mathur A, Inder TE 2008 Accuracy of bedside electroencephalographic monitoring in comparison with simultaneous continuous conventional electroencephalography for seizure detection in term infants. Pediatrics 121:1146-1154

8. Shellhaas RA, Soaita AI, Clancy RR 2007 Sensitivity of amplitude-integrated electroencephalography for neonatal seizure detection. Pediatrics 120:770-777

9. Niedermeyer E, Silva FLD (eds) 1999 Electroencephalograpy. Basic Principles, Clinical Applications, and Related Fields. Williams \& Wilkins, Baltimore

10. Woodward LJ, Anderson PJ, Austin NC, Howard K, Inder TE 2006 Neonatal MRI to predict neurodevelopmental outcomes in preterm infants. N Engl J Med 355:685694

11. Navelet Y, D'Allest AM, Ropert JC 1980 [E.E.G. appearances in 40 newborns with intraventricular hemorrhages (author's transl)]. Rev Electroencephalogr Neurophysiol Clin 10:19-20 [in French]

12. Tharp BR, Cukier F, Monod N 1981 The prognostic value of the electroencephalogram in premature infants. Electroencephalogr Clin Neurophysiol 51:219-236

13. Hellstrom-Westas L, Rosen I, Svenningsen NW 1991 Cerebral function monitoring during the first week of life in extremely small low birthweight (ESLBW) infants. Neuropediatrics 22:27-32

14. Olischar M, Klebermass K, Waldhoer T, Pollak A, Weninger M 2007 Background patterns and sleep-wake cycles on amplitude-integrated electroencephalography in preterms younger than 30 weeks gestational age with peri-/intraventricular haemorrhage. Acta Paediatr 96:1743-1750

15. Baumgartner C, Lurger S, Leutmezer F 2001 Autonomic symptoms during epileptic seizures. Epileptic Disord 3:103-116

16. Leutmezer F, Schernthaner C, Lurger S, Potzelberger K, Baumgartner C 2003 Electrocardiographic changes at the onset of epileptic seizures. Epilepsia 44:348354

17. Terndrup TE, Starr F, Fordyce WE 1994 A piglet model of status epilepticus: comparison of cardiorespiratory and metabolic changes with two methods of pentylenetetrazol administration. Ann Emerg Med 23:470-479

18. Cherian PJ, Blok JH, Swarte RM, Govaert P, Visser GH 2006 Heart rate changes are insensitive for detecting postasphyxial seizures in neonates. Neurology 67:22212223

19. Patrizi S, Holmes GL, Orzalesi M, Allemand F 2003 Neonatal seizures: characteristics of EEG ictal activity in preterm and fullterm infants. Brain Dev 25:427-437

20. Hellstrom-Westas L 1992 Comparison between tape-recorded and amplitudeintegrated EEG monitoring in sick newborn infants. Acta Paediatr 81:812-819 